Letter to the Editor

\title{
Can these older drugs bring new hope in Rheumatoid arthritis?
}

\author{
Babu L. N.*
}

Sir,

Rheumatoid Arthritis (RA) is an autoimmune disease characterized by chronic inflammation of joints. Currently one of the first line drugs used for RA is the drug Methotrexate (MTX) in low doses (5-25mg once in a week). Even though MTX is an antifolate drug, its action in RA is widely believed to be due to inhibition of the enzyme 5-aminoimidazole-4-carboxamide ribonucleotide (AICAR) Transformylase. ${ }^{1,2}$ A little deeper exploration of this drug, reveals that MTX by inhibiting the above enzyme, actually increases the levels of adenosine and it has been proven widely that adenosine produces a wide spectrum of anti-inflammatory effects like inhibition of neutrophil function, modulation of superoxide anion generation, modulation of cytokine release, inhibition of TNF alpha expression, enhancing interleukin-10 secretion there by suppressing inflammation in RA. ${ }^{2-9}$

With this concept, rationally a drug which can sustain the adenosine levels in this inflammatory milieu can produce sustained or effective anti-inflammation. Do we have a drug, which can sustain adenosine levels extracellularly? The answer is yes. The drug is Dipyridamole. The drug Dipyridamole has been known to be an adenosine reuptake inhibitor. Which means it can increase the adenosine levels extracellularly, by its reuptake inhibition action (that is the reuptake of adenosine extracellularly to intracellularly is inhibited). ${ }^{10-12}$

Hence a combination of MTX with Dipyridamole can sustain/increase adenosine levels at the inflammatory sites, thereby producing sustained or increased antiinflammatory effects, which can be over and above than either of these agents given alone. Hence logically this combination should provide better and faster healing of lesions in RA.

Another implication of this hypothesis is that, the drug MTX's toxicity can be decreased. MTX is used as low dose therapy due to its antifolate mechanism causing bone marrow suppression and the ensuing risk of infections. Hence this drug MTX if combined with Dipyridamole at a lower dose, it can cause lesser bone marrow suppression and hence lesser toxicity. But this combination can cause better anti inflammation, due to the presence of Dipyridamole which increases and sustains adenosine levels in the extracellular inflammatory sites, due to its action of reuptake inhibition of adenosine, the adenosine being produced by AICAR Transformylase inhibition caused by MTX. Hence the drug Dipyridamole can increase the sensitivity to MTX (drug synergism) in RA.

Hence a combination of these 2 drugs if investigated clinically and found successful can bring a new hope in the treatment of RA.

Babu L. N.*

Department of Pharmacology, Indira Gandhi Medical College \& Research Institute, Puducherry, India

*Correspondence to

Dr. Babu L. N.,

Email: bnarasimhaigmc@gmail.com

\section{REFERENCES}

1. Friedman B, Cronstein B. Methotrexate mechanism in treatment of rheumatoid arthritis. Jt Bone Spine Rev Rhum. 2018 Aug 3.

2. Allegra CJ, Drake JC, Jolivet J, Chabner BA. Inhibition

phosphoribosylaminoimidazolecarboxamide

transformylase by methotrexate and dihydrofolic acid polyglutamates. Proc Natl Acad Sci U S A. 1985 Aug;82(15):4881-5.

3. Baggott JE, Vaughn WH, Hudson BB. Inhibition of 5aminoimidazole-4-carboxamide ribotide transformylase, adenosine deaminase and 5'adenylate deaminase by polyglutamates of methotrexate and oxidized folates and by 5aminoimidazole-4-carboxamide riboside and ribotide. Biochem J. 1986 May 15;236(1):193-200.

4. Aminophylline for methotrexate-induced neurotoxicity. - PubMed - NCBI [Internet]. 2018 [cited 2018 Dec 22]. Available at: https://www.ncbi.nlm.nih.gov/pubmed/7776773

5. Cronstein BN, Eberle MA, Gruber HE, Levin RI. Methotrexate inhibits neutrophil function by stimulating adenosine release from connective tissue cells. Proc Natl Acad Sci USA. 1991 Mar 15;88(6):2441-5.

6. Cronstein BN, Kramer SB, Weissmann G, Hirschhorn R. Adenosine: a physiological modulator of superoxide anion generation by human neutrophils. J Exp Med. 1983 Oct 1;158(4):1160-77.

7. Differential regulatory effects of adenosine on cytokine release by activated human monocytes. PubMed - NCBI [Internet]. 2018 [cited 2018 Dec 22]. 
Available

at:

https://www.ncbi.nlm.nih.gov/pubmed/?term=Differe ntial+regulatory+effects+of+adenosine+on+cytokine +release+by+activated+human+monocytes.

8. Sajjadi FG, Takabayashi K, Foster AC, Domingo RC, Firestein GS. Inhibition of TNF-alpha expression by adenosine: role of A3 adenosine receptors. J Immunol Baltim Md 1950. 1996 May 1;156(9):3435-42.

9. Adenosine enhances IL-10 secretion by human monocytes. - PubMed - NCBI [Internet]. 2018 [cited 2018 Dec 22]. Available at: https://www.ncbi.nlm.nih.gov/pubmed/8666814

10. Balakumar P, Nyo YH, Renushia R, Raaginey D, Oh AN, Varatharajan R, et al. Classical and pleiotropic actions of dipyridamole: Not enough light to illuminate the dark tunnel? Pharmacol Res. 2014 Sep;87:144-50.

11. Ciacciarelli M, Zerbinati C, Violi F, Iuliano L. Dipyridamole: a drug with unrecognized antioxidant activity. Curr Top Med Chem. 2015;15(9):822-9.

12. Gamboa A, Abraham R, Diedrich A, Shibao C, Paranjape SY, Farley G, et al. Role of adenosine and nitric oxide on the mechanisms of action of dipyridamole. Stroke. 2005 Oct;36(10):2170-5.

Cite this article as: Babu LN. Can these older drugs bring new hope in Rheumatoid arthritis? Int J Basic Clin Pharmacol 2019;8:614-5. 